2012.12.19

\title{
WORKING
}

PAPER

"Creativity, organizational knowledge, and the power of dreams"

Francesco Schiavone

Parthenope University schiavone@uniparthenope.it

Manuel Villasalero

University of Castilla-La Mancha

manuel.villasalero@uclm.es

Submitted to the Journal of the Knowledge Economy on March 9, 2013 (accepted for publication on May 31, 2013).

Cite as: Schiavone, F. and Villasalero, M. (2013), "Creativity, organizational knowledge, and the power of dreams," Journal of the Knowledge Economy, 4, 279-292. DOI: $10.1007 / \mathrm{s} 13132-013-0159-2$ 


\section{Creativity, organizational knowledge, and the Power of Dreams}

Manuel Villasalero

Department of Business Administration; University of Castilla-La Mancha; Ciudad Real; Spain

Francesco Schiavone

Department of Business Studies; Faculty of Economics, University Parthenope; Naples; Italy

Department of Strategy and Management, ESG Business School; Paris; France

Corresponding author: Manuel Villasalero

Manuel.Villasalero@uclm.es

\section{Acknowledgments}

The authors are grateful for the cooperation of the Spain-based companies INDRA (www.indracompany.com/en) and TECNOBIT (www.tecnobit.es) without which this study would not have been possible. Special thanks to all the general managers and project managers who supported this study by providing information to the authors in the course of several interviews. We are also grateful to Professor Mark Batey for sending us the items composing the Biographical Inventory of Creative Behaviors.

\section{Abstract}

\begin{tabular}{|c|c|}
\hline Purpose & $\begin{array}{l}\text { This study addresses the question of how dreams might improve organizational } \\
\text { creativity in real world situations. Both Freudian and Jungian perspectives are } \\
\text { considered in a study that seeks to explore whether the personal unconscious } \\
\text { and the collective unconscious can be put to the service of high-tech companies. }\end{array}$ \\
\hline $\begin{array}{l}\text { Design/methodology } \\
\text { /approach }\end{array}$ & $\begin{array}{l}\text { A multiple case study methodology based on } 10 \text { projects from } 2 \text { companies shed } \\
\text { light on the role that intrinsic motivation (personal unconscious) and } \\
\text { organizational ideals (collective unconscious) play in the dreaming activity of the } \\
\text { project managers and the resulting overall creativity outcomes of the } \\
\text { corresponding projects. }\end{array}$ \\
\hline Findings & $\begin{array}{l}\text { With respect to the management of the personal unconscious, the findings } \\
\text { indicate that intrinsic motivation increases the emotional tone of dreams, which } \\
\text { in turn, contributes to overall project creativity. A more intrinsically-motivated } \\
\text { project manager is an emotional dreamer which is able to contribute to the } \\
\text { project creativity with innovative solutions derived from his/her dreams. With } \\
\text { regard to the management of the collective unconscious, the study shows that } \\
\text { project managers organize their project members around some organizational } \\
\text { ideals (hierarchy, group, team and clan) that may fuel or hamper project } \\
\text { creativity outcomes, thus conditioning the use of the collective unconscious. } \\
\text { Specifically, the project managers in charge of teams and clans are more creative } \\
\text { and emotional dreamers than those in charge of hierarchies and groups. }\end{array}$ \\
\hline Originality/value & $\begin{array}{l}\text { This study contributes to the knowledge of the role that so elusive antecedents } \\
\text { such as dreams might play in organizational creativity, innovation and change. } \\
\text { Instead of discussing about dreams in an abstract manner, the study focuses on } \\
\text { specific mechanisms (intrinsic motivation and organizational ideals) under the } \\
\text { control of senior managers. }\end{array}$ \\
\hline
\end{tabular}

Key-words: Dreams, Organizational Creativity, Unconscious, Ego-Ideal. 


\section{Creativity, organizational knowledge, and the Power of Dreams ${ }^{1}$}

\section{Introduction}

The subject of organizational creativity is a central stream of research within the fields of both innovation management (Alves et al., 2007; Bharadwaj and Menon, 2000) and organizational behavior (e.g. Amabile et al., 1996; Zhou and George, 2001). Organizational creativity refers to "the creation of a valuable, useful new product, service, idea, procedure, or process by individuals working together in a complex social system" (Woodman et al, 1993: p. 293). Innovation and change are processes strongly rooted in creativity (Ford and Ogilvie, 1996). Entrepreneurs can change market equilibriums and innovate by their capability of "creative destruction" (Schumpeter, 1934). Creativity is critical also to overcome tensions of organizational change (Seo, Putnam and Bartunek, 2004).

Organizations are able to change their routines, structures, and knowledge mainly by exploiting the creativity of their members or external partners. A number of papers by scholars in the field of innovation management analyzed the internal and external factors affecting organizational creativity (Sundgren et al., 2005a; Vissers and Dankbaar, 2002). Typical internal antecedents of creativity are organizational structure and strategy, resources, employees motivation and involvement, new technology and R\&D investments (Alves et al., 2007). Creativity depends by various factors at individual, group and organizational levels (Woodman et al., 1993). A type of antecedents to date scarcely analyzed by scholars refers to the unconscious dynamics of organizations and its members (Gabriel, 1995). In general, literature report a psychoanaIytical approach to the study of organizations should be a suitable theoretical background for the study of organizational change and the forces driving the change itself (Gabriel and Carr, 2002; de Swarte, 1998). In particular, various psychoanalysis scholars (e.g. Freud, 1962) cite the notion of dream in relation to creativity. Freud (1900) defines dreams as forms of "wish fulfillment", attempts by the unconscious to resolve a conflict of some sort, whether something recent or something from the recesses of the past. However, no empirical evidences tested the links between dreams and organizational creativity.

The present paper contributes to the extant literature on antecedents of organizational creativity by exploring the role played by dreams and unconscious on creative process. The research question of the paper, therefore, is: how do dreams improve organizational creativity? The paper reports the cases of two Spanish high-tech companies in order to satisfy this question. The main result of the study refers to evidence that the extent of dreams' impact on organizational creativity depends on some other antecedents/components, as intrinsic motivation and organizational ideals, of the creative process. Both individual (Freudian) and collective (Jungian) unconscious of the members of organizations are critical in order to manage effectively and improve organizational creativity and innovation. Drawing on the literature and the case studies, the paper advances two research propositions about the impact of dreams and unconscious on organizational creativity.

\footnotetext{
${ }^{1}$ Even though this paper is the product of unitary setup and reflection from both the authors, the fourth and sixth sections are attributed to Author 1 , the first, second and third sections are attributed to Author 2 . The fifth section was written by both the Authors.
} 


\section{Organizational Creativity and its Antecedents}

Organizational creativity is both a process and an outcome (Zhou and Shalley, 2009). Creativity typically "refers to idea generation, whereas innovation refers to idea implementation" (Rank et al., 2004: p 520). Two main theories explain the phenomenon of organizational creativity. In the field of organizational studies, Woodman, Sawyer and Griffin (1993) propose a theoretical framework in which organizational creativity depends on three types of characteristics:

- Individual characteristics: cognitive abilities, personality, intrinsic motivation, knowledge;

- Group characteristics: norms, size, diversity, roles, tasks, problem-solving approaches, cohesiveness;

- Organizational characteristics: culture, resources, rewards, strategy, structure, technology.

In this model, organizational creativity is the final product of a process. The combination of these three types of inputs leads to creative situations and creative behaviors. Creative situation is "the sum total of social and environmental (contextual) influences on creative behavior" (Woodman, Sawyer, and Griffin, 1993: p. 310) of individuals and groups. Both creative behavior and creative situation produce a creative product (novel ideas, products, services, procedures, or processes). Within the stream of literature about organizational innovation, Amabile (1996) proposes a componential theory of creativity. In this perspective, creativity depends on:

- three internal components (within the individual): intrinsic motivation, domain-relevant skills, creativity-relevant processes;

- one external component (outside the individual): the work environment.

Both these models imply different levels of creativity co-exist within (and can be supported by) an organization. Bharadwaj and Menon (2000) distinguish between individual and organizational creativity. Education and training programs (e.g. workshops) support individual creativity of employees. Typical organizational creativity mechanisms critical for innovation are, instead, management practices, use of teams, organization orientation. The presence of both organizational creativity mechanisms and individual creativity mechanisms is crucial in order to support innovation and change within organizations. However, also just organizational mechanisms (in absence of individual creativity mechanisms) can lead to positive innovation performances.

A wide set of research in the fields of innovation management, organizational behavior and applied psychology shed light on the various types of antecedents of organizational creativity. Triggers of organizational creativity may be internal or external and exploitable to solve specified problems or self-discovered problems (Unsworth, 2001). Typical external drivers of organizational creativity are the regional environment (Florida, 2003) and the multidisciplinary and multisectoral cooperation environments (Alves et al., 2007) of the company. Internal triggers of organizational creativity come from both individual and group conditions. At individual level, antecedent conditions (Woodman et al., 1993: p. 297) "influence the personality and cognitive characteristics of the individual, and to some extent they probably determine the current situation in which the individual find himself or herself". Typical antecedents of individual creativity are biographical backgrounds and past reinforcement history (learning) of individuals. Another key condition for 
individual creativity is intrinsic motivation. This notion refers to "the motivation to work on something because it is interesting, involving, exciting, satisfying, or personally challenging" (Amabile, 1997: p. 39). Within organizations, employees' individual creativity is the outcome of three components: task motivation, expertise and the creativity skills of the individual. The work environment has a relevant impact on individual creativity as it can enhance or repress these three components (Amabile, 1997). Job dissatisfaction may lead to organizational creativity of highly committed employees when they receive useful feedback and high support for creativity by co-workers and the organization itself (Zhou and George, 2001). Positive affect is a key antecedent of organizational creativity. A positive mood increases the creative thought; anger, fear and sadness are negatively related (Amabile and Mueller, 2008). Ryan and Deci (2000) in their "SelfDetermination Theory" argue that intrinsic motivation of an individual depends on three psychological needs: competence, autonomy and relatedness. Self-efficacy (and, in general, positive expectations of individuals about their capabilities) is another antecedent of individual creativity since it supports intrinsic motivation (Ford and Ogilvie, 1996).

At group level, creativity is more likely to emerge in groups in which members frequently exchange ideas each other. However, the possibility of processing and reflecting effectively about the ideas exchanged in the group is a critical condition to enhance the creativity of its members (Paulus and Yang, 2000). In relation to $R \& D$ teams, more conditions are considered drivers of a creative organizational climate (Sundgren et al., 2005b): learning culture, information sharing, intrinsic motivation, extrinsic motivation, evaluation and reflection, networking. In R\&D teams working in new product development the presence of more disciplines increases the group creativity. Also openness and external contacts affect positively the group creativity (Vissers and Dankbaar, 2002). King and Anderson (1990) consider leadership, cohesiveness, group longevity, group composition and group structure as antecedents for group creativity and innovation. However, R\&D groups develop creative products mainly by exploiting the creativity of their single members (Pirola-Merlo and Mann, 2004).

Applied psychology is another traditional theoretical field which contributed to the understanding of organizational and individual creativity. Potential internal predictors of organizational creativity are moderate extraversion and moderate action orientation of individuals; moderate charismatic leadership; organizational culture promoting low uncertainty avoidance, high individualism, high intellectual autonomy (Rank et al., 2004). Psychological states (e.g. positive emotions as happiness and joy) can be critical antecedents of individual creativity and impact positively on group creativity (Amabile and Mueller, 2008).

\section{Antecedents of Organizational Creativity and Dreams}

Psychoanalysis and the concept of dream might contribute to achieve a better understanding about organizational creativity and its antecedent conditions. Over the last two decades, various scholars found various potential areas of integration between management studies, organizational studies and psychoanalysis. In general, de Swarte (1998) argues that management of change is one of the most suitable research areas for the adoption of a psychoanalytical approach to study organizations. The psychoanalytic approach analyzes the unconscious causes of behavior at both individual and organizational level. Such approach provides a complementary perspective to study the "underlying dynamics" that work within formal organizations (Willcocks and Rees, 1995). Behind every organization there is always an unmanaged organization, "an organizational dreamworld in which desires, anxieties and emotions find expressions in highly irrational con- 
structions" (Gabriel, 1995). In this light, dreams, fantasies and myths play a critical role in the organizational daily life: "fantasy can offer...a refashioning of official organizational practices in the interest of pleasure, allowing a temporary supremacy of emotion over rationality and of uncontrol over control" (Gabriel, 1995: p. 479).

Referring to organizational creativity, Gabriel and Carr (2002) report that organizations have various psychoanalytical foundations. One of them relates to the fact that organizations act also to implement collective and shared visions and to stimulate creativity. Indeed, organizations offer "creative outlets" based on an organizational ideal, an idealized image of organization which is characterized by numerous desirable qualities. Such ideal of the organization often becomes an ego-ideal of its members and can affect their intrinsic motivation.

Dreams, of course, are unpredictable and, therefore, are hard to consider as a manageable resource or an input of organizational creativity under corporate control. Dreams are "the most common and most normal expression of the unconscious psyche, they provide the bulk of the material for its investigation" (Jung, 1974 , p. 73). Unconscious is viewed as the shadow of conscious mind. Unconscious is the "matrix of dreams", an unknown background in which dreams' roots lie.

Dreaming is often cited as a phenomenon closely related to creativity. Taylor (1983: p. 8) writes that "since the dawn of written history, dreams have served as primary vehicle for human creativity and increasing self-awareness". Piaget (1951) argues in children dreams themselves are the result of a creative process of construction and give opportunity for free experimentation and finding of creative new solutions. Literature often recognized the link between dreams and creativity for artistic creations. Barrett (1993) reports various cases: the Italian violinist Giuseppe Tartini composed his masterpiece "Devil's Trill sonata" after dreaming he sold his soul to the devil; Robert Louis Stevenson had many ideas for "Doctor Jeckill and Mister Hide" by dreaming. Dreams could enhance problem solving by suggesting creative solutions. For instance, the German chemist Friederich Kekule claimed his Nobel-prize winning realization of the atomic structure of the benzene molecule as hexagonal rather than straight came after dreaming of a snake grasping its tail in its mouth.

This reasoning is consistent with the findings of the two key scholars within this field of study: Sigmund Freud and Carl Jung. On the one hand, Freud studied the creative process in both ordinary and eminent people. Freud argues unconscious is personal and is the domain of mental activity that lay below the "surface" of every individual. The intrinsic motivation of individuals to fulfill (often unconscious) personal desire orients their emotions, fantasies and dreams toward the search of creative solutions to achieve this goal. Freud in the lecture about "Creative writers and Day-Dreaming" (1962) notes that:

"The creative writer does the same as the child at play. He creates a world of fantasy which he takes very seriously--that is, which he invests with large amounts of emotion--while separating it sharply from reality".

On the other hand, Carl Jung argues dreams are involuntary products of the unconscious psyche and are affected by collective unconscious, common to human beings sharing same culture. Jung (1959, p. 59) states that "dreams often contain fantasies which 'want' to become conscious" and are not under any conscious control. According to Jung, collective unconscious is an untapped source of positive, adaptive and creative potential. Jung $(1959$, p. 55) argues that: 
"in addition to our immediate consciousness, which is of a thoroughly personal nature and which we believe to be the only empirical psyche (even if we tack on the personal unconscious as an appendix), there exists a second psychic system of a collective, universal, and impersonal nature which is identical in all individuals. This collective unconscious does not develop individually but is inherited. It consists of pre-existent forms, the archetypes, which can only become conscious secondarily and which give definite form to certain psychic contents."

Jung's archetypes are similar to logical categories (e.g. "the good employee"). Over time working within an organization can encourage in some individuals the interiorization of these collective categories and a strong identification with the organizational ideals based on specific behaviors and values (Carr, 2002). This process is likely to shape common unconscious pressures between the organization members orienting their dreaming activity and creative potential.

Therefore, the main divergence between Freud's and Jung's views is the nature of unconscious: personal for Freud, collective for Jung. These perspectives suggest dreams represent both personal unconscious (latent personal wishes) and collective unconscious (archetypes). Emotions play a key role in orienting dreams and creativity for both the authors.

\section{Case Studies}

\section{Methodological Notes}

Two large research facilities in Spain were selected in order to carry out a multiple case study investigation of the role dreams might play in organizational creativity. One of the research facilities is a software laboratory located at the heart of a university campus in which more than 500 computer science engineers develop innovative software projects in different markets, such as public administration, healthcare, insurance or energy. This software lab is integrated into a network of 12 software labs worldwide in which it plays a focal role and belongs to the Spain-based multinational INDRA, which is the second largest information technology company in Europe. The other research facility is a hardware factory of electronic products for the defense and space industries located 60 kilometers away from the previous facility in which more than 200 hardware and software engineers develop advanced electronic systems for aircrafts, boats and satellites. This hardware factory is property of the Spain-based multinational TECNOBIT, which is one of the major players in the European electronic defense industry. The fact that we chose a software facility and a hardware facility was intentional in order to get a more complete picture of the phenomenon under study. The small distance between both facilities was also a decision made with the purpose of preventing any confounding effects due to geographical cultures. Both industries share a context very much marked by technological change and innovation.

We asked the general managers of the software lab and the hardware factory to select a sample of representative projects conducted in those research facilities which were just finished or near finished at the beginning of 2012. The general managers were instructed to select projects with varying degrees of innovation, defined as the level to which the projects produced innovative, creative solutions which were largely unexpected in the initial programming of the project. In this way, the sample of research projects assured enough variability to consider not only creative outcomes, but also the role that creative processes might play from an organizational change management perspective. A total amount of 10 projects were finally se- 
lected, 7 projects from the software lab (INDRA) and 3 projects from the hardware factory (TECNOBIT). Our unit of analysis was the project because it allowed us to explore creativity issues at both individual and group levels.

The data for the present study was collected in the course of several semi-structured interviews with general managers, project leaders and team members, thus covering different level of analysis. The interviews were administered by one of the authors in the first months of 2012 as a part of a larger research effort dealing with managing organizational creativity in high-tech companies. The typical interview format was a very frank and direct conversation between the interviewer and the interviewees about the major determinants of creativity within organizations and the manners through which creativity, innovation and change are all interconnected. Despite there was a well-defined interview script, the interviewer let the interviewees enough room as to change freely from one topic to another and go forth and back. This case study methodological approach allowed us to address simultaneously both process and outcome accounts of organizational creativity with the appropriate depth.

The interview script was designed taking into account well-known instruments in the measurement of the focal variables, such as creativity, dreams, intrinsic motivation and organizational ideals. Despite the present research was not intended to be a quantitative study, quantitative scales allowed us to drive the interviews. In the case of dreams, we used some questions from Schredl (2002), Schredl and Erlacher (2007) and Beaulieu-Prévost and Zadra (2005). For creativity, some questions taken from the Biographical Inventory of Creative Behaviors (Batey, 2007) proved very useful. Finally, some variations of the exercises proposed by Boozer and Forte (2004) to identify organizational ideals in accordance with the underlying Jungian types were also used.

Both senior managers and project managers were asked to assess the level to which the sampled projects were creative on a six-point scale (from $0=$ very low to $6=$ very high). The correspondence of both assessments were very high (Pearson's $r=0.78, p<0.001$ ) and, as expected, the self-assessments made by project managers were higher than the assessments made by senior managers. Throughout this study, we use the independent assessment of senior managers. Following Schredl (2002), we also asked the project managers the level to which their dreams had creative aspects on a five-point scale (from $1=$ no creative aspects to $5=$ many creative aspects), the overall emotional tone of their dreams $(-1=$ predominantly negative, $0=$ balanced $+1=$ predominantly positive) and the realism of their dreams $(0=$ non-realistic dreams, 1 = dreams are sometimes realistic, 2 = dreams are often realistic). The Work Preference Inventory (Amabile, Hill, Hennessey and Tighe, 2004, 2005) was administered to project managers as a measure of intrinsic motivation (30 items on a four-point scale ranging from $1=$ never or almost never true of me to $4=$ always or almost always true of me, with sample questions such as "I enjoy tracking problems that are completely new to me").

\section{Case Studies}

After various preliminary conversations with four senior managers (two per company which occupies positions ranging from general manager to operation manager) about the manner in which projects were organized in each company and a first round of interviews with project managers, we identify four organizational ideals within our research setting: hierarchy, group, team and clan. The hierarchy-like organizational ideal is based on a rigid distribution of tasks amongst the project members, a great deal of centralization of decision-making and an extensive use of formal reporting to the project manager. The group-like organiza- 
tional ideal is less hierarchically oriented inasmuch there are neither clear vertical layers nor rigid division of labor within the project, the project members work laterally to a large extent and the project manager is usually involved trying to solve some specific issues. The team-like organizational ideal is quite similar to the group-like, but the division of labor is almost none and the project manager is no longer involved trying to solve specific issues. Finally, the clan-like organizational ideal is not only the most organic manner in which to organize the project, but it is also the archetype in which the project members' sense of belonging, mutual support, empathetic behavior and friendship relations are the rule, with a project manager very much involved emotionally with his/her project members. In the course of the interviews, the interviewees were asked about the ideal manner in which they would organize their project members assuming there were no barriers to do so. As a result of these explanations, the interviewer classified the project manager in one of the four categories without having detailed the categories to them previously. A couple of days later, a brief personal report was sent to the project managers with a full explanation of the four categories and his/her classification into one of them. 7 out of 10 project managers explicitly agreed that the classification was correct, and the remaining 3 project managers agreed with the classifications after some further explanations. The classifications were also cross checked with a senior manager from each company and no changes were deemed necessary. It is important to note that organizational ideals seemed to be working as organizational realities since that project managers did not find major problems when they tried to implement their organizational ideals. The most widely cited obstacle was time pressure and some of them would like to have more freedom to select the member teams.

A comparison of project creativity, creative dreams and dream emotional tone across the four organizational ideals reveals some interesting findings on the role of collective unconscious (table 1).

Table 1. Creativity, dreams and organizational ideals*

\begin{tabular}{|l|r|r|r|r|}
\hline $\begin{array}{l}\text { Organizational } \\
\text { Ideal }\end{array}$ & $\mathrm{N}$ & \multicolumn{1}{|c|}{$\begin{array}{c}\text { Dream } \\
\text { creativity }\end{array}$} & $\begin{array}{c}\text { Dream emotio- } \\
\text { nal tone }\end{array}$ & $\begin{array}{c}\text { Project creativi- } \\
\text { ty }\end{array}$ \\
\hline Hierarchy & 3 & 2,33 &, 00 & 1,67 \\
\hline Group & 2 & 2,00 &, 00 & 4,00 \\
\hline Team & 2 & 3,50 & 1,00 & 3,50 \\
Clan & 3 & 3,33 &, 33 & 5,00 \\
\hline Total & 10 & 2,80 &, 30 & 3,50 \\
\hline
\end{tabular}

* Mean values

The clan-like project organizations outperform the hierarchy-like project organizations in terms of overall project creativity, while groups and teams are close followers of clans $(F=3.782, p=.078)$. On the other hand, project managers in charge of teams and clans are more creative and emotional dreamers than those in charge of hierarchies and groups $(F=4.109, p=.067 ; F=4.300, p=.061)$. This relationship among organizational ideals, project creativity and dream activity was the most valuable finding deriving from the present study and gives preliminary support to Jungian ideas. 
Our study also found support for the role of personal unconscious. Despite there is no relation between creative dreams and intrinsic motivation, the project managers' intrinsic motivation made a negative impact on the realism of dreams (Pearson $r=-.52, p=.058$ ) and a positive impact on the overall emotional tone of dreams (Pearson $r=.53, p=.058$ ). Thus, intrinsically motivated project managers have more abstract and more emotional dreams than their extrinsically motivated counterparts. There is also a positive relation between emotional dreams and project creativity outcomes (Pearson $r=.624, p=.027$ ) and a weaker link between internal motivation and project creativity outcomes (Pearson $r=.473, p=.84$ ). These exploratory findings suggest than intrinsic motivation increases the emotional tone of dreams, which in turn, contributes to overall project creativity.

\section{Psychoanalytic Interpretation}

This section develops two research propositions about the role played by unconscious and dreams on organizational creativity. The propositions flow from the literature and the qualitative analysis simultaneously. Drawing on both the views of Freud and Jung, two levels of analysis are considered in the following: personal unconscious and collective unconscious.

\section{Personal Unconscious}

From a Freudian perspective, individuals working intensively on a specific task might find in their personal unconscious the solution for problems. Dreams could provide to very motivated individuals a creative "image" of how to solve organizational problems. Such vision is the outcome of unconscious dynamics that develop solutions not developed through the conscious mind of the individual. Successful artists and brilliant scientists are usually very talented people motivated and committed in their creative work. Deep motivation and commitment in the job are likely to make them focused not just consciously but often even unconsciously on their creative process. The link between conscious and unconscious for these people are emotions. A high intrinsic motivation to solve a problem or define a creative output brings about in these persons positive emotions and feelings (e.g., self-satisfaction, increase of self-efficacy) in case of success. The same emotions are the "keys" by which these talented individuals enter in a sort of "personal fantastic dreamworld", centered around the problem and its possible solutions, from which they cannot disconnect easily neither in their night sleeping nor day rest. These examples show also that experience, in combination with intrinsic motivation, can lead these persons to dream (or even dream-day) creative solutions and inspirations for their works. Tartini composed the "Devil's Trill sonata" when he was almost sixty years old. Stevenson wrote his book in 1886 (at the age of 36 years old) after 16 years of career as writer. Kekule in a daydream solved the problem on which he worked for years (Barrett, 1993).

In other words, intrinsic motivation of individuals for their job is likely to increase the creative potential of their personal unconscious. Therefore, the following proposition can be posit:

P1: intrinsic motivation of individuals stimulates the support of their personal unconscious to organizational creativity.

The case studies showed that intrinsic motivation promotes emotional dreaming which, in turn, fosters project creativity outcomes. Therefore, the emotional tone of dreams is the psychoanalytic force through which an internally-motivated project manager put the personal unconscious to the service 
of organizational creativity. For example, a highly internally-motivated project manager reported a repetitive nightmare in which the failure to miniature a component in the context of an ongoing project determined the closure of the whole facility. The conscious consequence of this emotional dream was that the project manager focused the attention of the project members into the issue of miniaturization. Another internally-motivated project manager reported an intense dream in which he was playing a decisive paddle and he and his teammate were unable to get the ball pass and hit the court until they changed their places and started to play backhand. The conscious consequence of this emotional dream was that the project manager found a way to optimize a database search algorithm (reversing some searching flows) in the context of a project in which the players in the dreamed match were members of that project. These two examples shows that internally-motivated project managers take their conscious job worries to the unconscious scope of dreams, in which they sometimes find creative levers for real world solutions.

\section{Collective Unconscious}

From a Jungian perspective, dreams are the outcome of some collective unconscious widespread in the social context of the dreamer. This second type of unconscious reveals the possibility that characteristics of the work environment might affect somehow the creative function of individuals' dreaming. In particular, organizational ideals could provide the basis for collective unconscious pressures to their members as they might shape an idealized image in its members. If such ideals are shared within the organization they become a sort of Jungian archetypes by providing an unconscious collective pressure to the each organization member. An organizational ideal corresponds to and has origins in an individual's ego ideal (Schwartz, 1987). Individuals will transform organizational ideals in ego ideals and improve commitment and motivation for their work (Gabriel and Carr, 2002). The final outcome of this process might bring about an improvement of the creative function of individual dreams. Organizational ideals might be related to the whole organization or to the group in which the dreamer work (e.g. a R\&D team). Therefore, the following proposition can be posit:

P2: organizational ideals stimulate the support of collective unconscious to organizational creativity.

As was the case with the first proposition, the qualitative methodology shed also light on the psychoanalytic mechanism that links organizational ideals and organizational creativity, resulting that emotional dreaming occupies again a central role in the explanation of that linkage. Our findings showed that the clan-like organizational ideal is the best organizational solution to deal with creative demanding projects (contrary to hierarchy-like organizational ideal, which is the worst solution to handle creative requirements) and clans are all about emotions and commitment with the project requirements as well as amongst the project members. In the context of clans, the division of labor is almost inexistence, the project manager is very much involved emotionally with his/her project members and there is a widespread sense of belonging, mutual support, empathetic behavior and friendship relations abounds amongst the project members. In this collective setting, we found that the project managers have emotional and creative dreams. Interestingly, the project managers that support clan-like organizations reported dreams in which they are able to identify some project members playing different roles, many times in the context of teamwork activities, such as playing a paddle match, climbing a mountain or passing through a river. This type of dream is simply inexistent in the case of project managers that favor hierarchy-like organizational ideals. 
Moreover, the three project managers with a hierarchy-like organizational ideal reported that they did not remember specific ways through which a dream might help them to deal with project-related problems. None of them recalled neither that some emotional dreams had led them to make important decisions. What is even more interesting, none of them reported significant issues with getting unplugged from workrelated problems. The pattern is almost the inverse in the case of the project managers with a clan-like organizational ideal. Two of the three project managers did remember explicitly how specific dreams have helped them to solve specific problems and the remaining project manager recognized that he knew that his dreams were helping him because he was able to solve project-related issues in the mornings that came after intense dreaming nights. The three project managers faced big issues to get unplugged from work and they usually took their work-related problems to bed. The pattern of project managers with either group or team ideals was blurred with some of them resembled the clan pattern and others resembled the hierarchy pattern.

In summary, dreams are the final outcome of pressures by both personal unconscious and collective unconscious of the dreamer. The impact of such pressures on the individual ability to achieve creative "problemsolving" solutions depends on other typical antecedents of organizational creativity. The more other components of creativity (namely, intrinsic motivation and organizational ideals) increase the psychological pressure on an individual, the more his/her unconscious is likely to dream creative solutions for his/her organization.

\section{Conclusions}

This study was intended as a exploratory investigation of the role that creative dreams might play in creative outcomes and creative processes within the context of project-based organizations. Following the ideas advanced by Freud and Jung, the personal and collective unconscious might be put to the service of tangible outcomes, such as those related to creativity, change and innovation in high-tech companies. A multiple case study methodology with 10 projects from 2 companies shed light on the management of both personal and collective unconscious in the benefit of organizational creativity and innovation.

With respect to the management of the personal unconscious, our study indicates that internally motivated managers have more abstract and emotional dreams than those managers externally motivated. Inasmuch that emotional dreams seem to play a role in explaining overall creative project outcomes, it follows that senior managers might put the personal unconscious to the service of the more demanding projects in terms of creativity if they assign them to internally motivated project managers. As suggested by Amabile et al. $(1994,1995)$, internally motivated managers are those persons that enjoy their jobs and obtain psychological rents from embarking on challenging projects (Stuhlfaut, 2010). If senior managers are able to match the motivational profile of project managers to the creative demands of projects, they will put the personal unconscious of those managers to the benefit of the project outcomes.

The findings regarding the management of collective unconscious are even more interesting, as our study shows that project managers organize project members around some organizational ideals that may fuel or hamper project creativity outcomes, thus conditioning the use of the collective unconscious. The adoption of hierarchies does not contribute to project creativity at all, while the adoption of clans signifies a bit step forward in terms of project creativity outcomes. The use of groups and teams are somewhat in the middle 
between hierarchies and clans. The managerial implications are straightforward; senior manager has to monitor the internal organizational design and behavior of the ongoing projects in accordance of the creativity demands of each project. Probably, the best manner of doing so is to select the appropriate project manager and leave his/her freedom to organize the project members according to his/her organizational ideal.

An interesting question is whether the project managers could have enough capacity to choose their project members and, in some cases, they must have to be entitled to discard a project member even when the project has been initiated. Our study findings suggest than project manager with clan organizations must have more freedom when they are face with the decision of configuring the project members. Otherwise, the trust, sense of belonging and friendship relations which are typical of clans could not emerge. Similarly, the stability of team members throughout several projects is also important in the configuration of clans.

The findings parallel those previously obtained on the conscious processes of change and innovation in the context of project-based organizations, but they also extend the domain of these important issues into the scope of the unconscious. The present study is an exploratory investigation of a elusive phenomenon such as how dreaming might contribute to organizational outcomes and processes. The findings are thus conditioned by the explorative nature of this study, in which a compromise between breadth and depth was intentionally assumed in favor of the later. The limitations are derived from the multiple case study methodology that we employed to shed light on the role of personal and collective unconscious in organizational creativity, change and innovation. Future studies might build on the present research to enlarge the number of case studies and to undertake quantitative investigations of the relations uncovered in this exploratory study. 


\section{References}

Alves, J., Marques, M.J., Saur, I. and Marques, P. (2007), "Creativity and innovation through multidisciplinary and multisectoral cooperation", Creativity and Innovation Management, Vol. 16 No. 1, pp. 2734.

Amabile, T.M. (1996), Creativity in Context: Update to the Social Psychology of Creativity, Westview Press, Boulder, CO.

Amabile, T.M. (1997), "Motivating creativity in organizations: On doing what you love and loving what you do", California Management Review, Vol. 40 No 1, pp. 39-58.

Amabile, T.M. and Mueller, J. (2008), "Assessing creativity and its antecedents: An exploration of the componential theory of creativity", in Zhou, J. and Shalley, C.E. (Eds.), Handbook of Organizational Creativity, Lawrence Erlbaum Associates, Mahwah, NJ,

Amabile, T.M., Conti, R., Coon, H., Lazenby, J. and Herron, M. (1996), "Assessing the work environment for creativity", Academy of Management Journal, Vol. 39 No. 5, pp. 1154-1184.

Amabile, T.M., Hill, K.G., Hennessey, B.A. and Tighe, E.M. (1994), "The work preference inventory: Assessing intrinsic and extrinsic motivational orientations", Journal of Personality and Social Psychology, Vol. 66 No. 5, pp. 950-967.

Amabile, T.M., Hill, K.G., Hennessey, B.A. and Tighe, E.M. (1995), "The work preference inventory: Assessing intrinsic and extrinsic motivational orientations: Correction", Journal of Personality and Social Psychology, Vol. 68 No. 4, pp. 580.

Barrett D. (1993), "The "committee of sleep": A study of dream incubation for problem solving", Dreaming, Vol. 3, No. 2, pp. 115-123.

Batey, M. (2007), A Psychometric Investigation of Everyday Creativity, Unpublished Doctoral Thesis, University College, London.

Beaulieu-Prévost, D. and Zadra, A. (2005), "Dream recall frequency and attitude towards dreams: A reinterpretation of the relation", Personality and Individual Differences, Vol. 38 No. 4, pp. 919-927.

Bharadwaj, S. and Menon, A. (2000), "Making innovation happen in organizations: Individual creativity mechanisms, organizational creativity mechanisms or both?", Journal of Product Innovation Management, Vol. 17 No. 6, pp. 424-434.

Boozer, R.W. and Forte, M. (2004), "Two exercises for exploring the relationships among Jungian psychological types, organizational ideals, and organizational politics perceptions", Journal of Management Education, Vol. 28 No. 3, pp. 390-403.

Carr, A. (2002) "Jung, archetypes and mirroring in organizational change management: Lessons from a longitudinal case study", Journal of Organizational Change Management, Vol. 15 No. 5, pp. 477-489.

de Swarte, T. (1998), "Psychoanalysis and management: The strange meeting of two concepts", Journal of Managerial Psychology, Vol.13 No.7, pp.459-68. 
Florida, R. (2003), The Rise of the Creative Class, Basis Books, New York, NY.

Ford, C.M. and Ogilvie, D.T. (1996), "The role of creative action in organizational learning and change", Journal of Organizational Change Management, Vol. 19 No. 1, pp. 54-62.

Freud, S. (1900), The Interpretation of Dreams, MacMillan, New York, NY.

Freud, S. (1962). "Creative writers and daydreaming". In J. Strachy (Ed.), The standard edition of the complete psychological works of Sigmund Freud (Vol. 9, pp. 142-152). London: Hogarth. (Original work published 1908).

Gabriel, Y. (1995), "The unmanaged organization: Stories, fantasies and subjectivity", Organization Studies, Vol. 16 No. 3, pp. 477-501.

Gabriel, Y. and Carr, A. (2002), "Organizations, management and psychoanalysis: An overview", Journal of Managerial Psychology, Vol. 17, no. 5, pp. 348-365.

Jung, C.G. (1959), "The concept of the collective unconscious", In The archetypes and the collective unconscious, collected works (Vol. 9, Part 1, pp. 54-74). Princeton, NJ: Princeton University Press. (Original work published 1936).

Jung, C.G. (1974), Dreams, Princeton, NJ: Princeton University Press.

King, N. and Anderson, N. (1990), "Innovation in working groups", in West, M.A. and Farr, J.L. (Eds.), Innovation and Creativity at Work, Wiley, Chichester, pp. 81-100.

Paulus, P.B. and Yang, H.C. (2000), "Idea generation in groups: A basis for creativity in organizations", Organizational Behavior and Human Decision Processes, Vol. 82 No. 1, pp. 76-87.

Piaget, J. (1951), Play, Dreams and Imitation in Childhood, Norton, New York, N.Y. (original work published 1946).

Pirola-Merlo, A. and Mann, L. (2004), "The relationship between individual creativity and team creativity: aggregating across people and time", Journal of Organizational Behavior, Vol. 25 No. 2, pp. 235257.

Rank, J., Pace, V.L. and Frese, M. (2004), "Three avenues for future research on creativity, innovation, and initiative", Applied Psychology, Vol. 53 No. 4, pp. 518-528.

Ryan, R.M. and Deci, E.L. (2000), "Self-determination theory and the facilitation of intrinsic motivation, social development, and well-being", American Psychologist, Vol. 55 No. 1, pp. 68-78.

Schredl, M. (2002), "Questionnaires and diaries as research instruments in dream research: methodological issues", Dreaming, Vol. 12 No. 1, pp. 17-26.

Schredl, M. and Erlacher, D. (2007), "Self-reported effects of dreams on waking-life creativity: An empirical study", Journal of Psychology, Vol. 141 No. 1, pp. 35-46.

Schumpeter, J.A. (1934), The Theory of Economic Development, London, Oxford University Press. 
Schwartz, H.S. (1987), "Anti-social actions of committed organizational participants: An existential psychoanalytic perspective", Organization Studies, Vol. 8 No. 4, pp. 327-340.

Seo, M.G., Putnam, L.L. and Bartunek, J.M. (2004), "Dualities and tensions of planned organizational change", in Poole, M.S. and Van de Ven, A.H. (Eds.), Handbook of Organizational Change and Innovation, Oxford University Press, New York, NY, pp. 73-107.

Stuhlfaut, M.W. (2010), "Evaluating the work preference inventory and its measurement of motivation in creative advertising professionals", Journal of Current Issues and Research in Advertising, Vol. 32 No. 1, pp. 81-93.

Sundgren, M., Dimenäs, E., Gustafsson, J.E. and Selart, M. (2005a), "Drivers of organizational creativity: A path model of creative climate in pharmaceutical R\&D", R\&D Management, Vol. 35 No. 4, pp. 359 374.

Sundgren, M., Selart, M., Ingelgard, A. and Bengtson, C. (2005b), "Dialogue-based evaluation as a creative climate indicator: Evidence from the pharmaceutical industry", Creativity and Innovation Management, Vol. 14 No. 1, pp. 84-98.

Taylor, J. (1983), Dream Work: Techniques for Discovering the Creative Power in Dreams, Paulist Press, Mahwah, NJ.

Unsworth, K. (2001), "Unpacking creativity”, Academy of Management Review, Vol. 26 No. 2, pp. 289-297.

Vissers, G. and Dankbaar, B. (2002), "Creativity in multidisciplinary new product development teams", Creativity and Innovation Management, Vol. 11 No. 1, pp. 31-42.

Willcocks, S.G. and Rees, C.J. (1995), "A psychoanalytic perspective on organizational change”, Leadership \& Organizational Development Journal, Vol. 16 No. 5, pp. 32-37.

Woodman, R.W., Sawyer, J.E. and Griffin, R.W. (1993), "Toward a theory of organizational creativity", Academy of Management Review, Vol. 18 No. 2, pp. 293-321.

Zhou, J. and George, J.M. (2001), "When job dissatisfaction leads to creativity: Encouraging the expression of voice", Academy of Management Journal, Vol. 44 No. 4, pp. 682-696.

Zhou, J. and Shalley, C.E. (2009), "Deepening our understanding of creativity in the workplace: A review of different approaches to creativity research", in Zedeck, S. (Ed.), APA Handbook of Industrial and Organizational Psychology, American Psychological Association, Washington, D.C., pp. 275-302. 